Original Article

\title{
EFFECT OF MUCUNA COCHINCHINENSIS EXTRACTS ON EFFLUX PUMP IN FUNGAL STRAINS
}

\author{
NATARAJAN K. ${ }^{*}$, KUMARESH JAWAHAR N. ${ }^{2}$ \\ ${ }^{1}$ Department of Pharmaceutical Biotechnology, T John College of Pharmacy, Bengaluru, ${ }^{2}$ Department of Biotechnology, SASTRA \\ University, Tanjore \\ Email: kumareshjawahar231@gmail.com
}

Received: 15 Mar 2020, Revised and Accepted: 19 May 2020

\begin{abstract}
Objective: To study the efflux pump inhibition activity of Mucunacochinchinensis extracts

Methods: Sensitivity assay was performed by Kirby Bauer technique. Effluxing ability of microbe was done by accretion, accumulation and efflux pump assays.

Results: Resistant fungal strains were subjected to efflux ability studies. Maximum effluxing ability was determined from the experimental data and it was found to be $105 \mathrm{~min}$ and $75 \mathrm{~min}$ by Candida albicans for methanolic extract of M. cochinchinenesis (MMC) and ethanolic extract of M. cochinchinensis (EMC) respectively and 45 min and 105 min by Aspergillus niger for MMC and EMC respectively. Profound synergistic effect of inhibition was observed with combined MMC and standard Clotrimoxazole when compared to the standard alone; against $C$. albicansindicates the modulating efficacy of MMC.
\end{abstract}

Conclusion: M. cochinchinensis extracts showed efflux pump modulating activity.

Keywords: Mucunacochinchinensis, Efflux pump, Fungal strains

(C) 2020 The Authors. Published by Innovare Academic Sciences Pvt Ltd. This is an open access article under the CC BY license (http://creativecommons.org/licenses/by/4.0/) DOI: http://dx.doi.org/10.22159/ijcpr.2020v12i4.39090. Journal homepage: https://innovareacademics.in/journals/index.php/ijcpr

\section{INTRODUCTION}

According to National Institute of Allergy and Infectious diseases, microbial infections are the second most (26\%) next to cardiovascular diseases (29\%) common cause for overall deaths. Deaths among infections, respiratory infection stands first followed by HIV, diarrheal, tuberculosis, vaccines preventable childhood diseases, malaria, STD, meningitis, hepatitis B and C, tropical parasitic disease, dengue and other infections. Extensive researches are being in progress to defend these infections from natural sources. However existing antimicrobial groups are effective, but the need for constant and continuous research is due to the wide spectrum of chemo-resistance developed by microbes [1]. The loss of effective antibiotics will undermine our ability to fight infectious diseases and manage the infectious complications common in vulnerable patients undergoing chemotherapy for cancer, dialysis for renal failure and surgery, especially organ transplantation, for which the ability to treat secondary infections is crucial [2].

When first line and then second-line antibiotic treatment options are limited by resistance or unavailable, healthcare providers are forced to use antibiotics that may be more toxic to the patient and frequently more expensive and less effective. To nullify these problems natural sources like plant and marine need to be bioprocessed for their effectiveness as antimicrobial or as resistant modulators. Usually nature has defending ability to invade foreign objects and frequent changes will be there for adaptation to survive.

Mucuna genus belongs to the family Fabaceae. This is the second largest family of flowering plants and contains 600 genera and about 12000 species [3]. The seeds are traditionally used as nervine tonic, emmenagogue, astringent, aphrodisiac, leucorrhea and paralysis. The hairs of the pods are vermifuge and treated for round worm infections. Mucunamonosperma is used as an expectorant and sedative given in cough and asthma [4]. In Ayurveda they are useful in vitiated conditions of vata and pitta, constipation, nephropathy, strangury, dysmenorrhea, amenorrhea, elephantiasis, dropsy, neuropathy, ulcers, helminthiasis, fever, delirium and for treating Parkinson's disease. Antibacterial activity of methanolic extract of Mucunapruriens was evaluated and well documented the broad- spectrum activity against all strains used [5]. The methanolic extract of Mucunamonosperma seeds were evaluated for its antibacterial activity. The result was broad spectrum as it showed activity against Gram positive Bacillus cereus, Staphylococcus and Gram-negative Proteus vulgaris [6].

\section{MATERIALS AND METHODS}

\section{Plant collection and authentication}

The matured seeds were collected from Western Ghats, Mundanthurai, Tamilnadu during the month of February after winter season. The flowering occurred in the month of December and the pods are matured only at February. Care was taken to select healthy, normal and even size seeds while collection. The collected seeds were authenticated by renowned botanist and a voucher specimen (UCP/MS-0118) was deposited in Department of Pharmacognosy, Ultra College of Pharmacy, Madurai.

\section{Preparation of plant extract}

The seeds were dried in shade and powdered in a mechanical grinder. About $250 \mathrm{~g}$ of dried seed powder was extracted by cold maceration using shaker for $72 \mathrm{~h}$ in $1.0 \mathrm{~L}$ of methanol and $1.0 \mathrm{~L}$ of ethyl acetate. The methanol extract (MMC) and ethyl acetate extract (EMC) of $M$. cochinchinensis were concentrated in rotary vacuum evaporator and preserved in tightly closed container [7].

\section{Preparation of seed extract}

Simple cold maceration process was adopted to extract desired compounds from Mucunacochinchinensis seeds recommend by standard reference mentioned in procedure part. Methanolic extract and ethyl acetate extract of $M$. cochinchinensis were designated as MMC and EMC respectively. The extractive percentage yield of MMC and EMC was found to be 5.7 and $4.3 \% \mathrm{w} / \mathrm{w}$. Two different solvents methanol and ethyl acetate were used for the study. Even though polarity of the above-mentioned solvents is seems to be same the induced polarizability of methanol is very high compared to ethyl acetate due to their varied dielectric constant $32.6 €$ and $6.02 €$ [8]. This imparts in the extractive values that methanol shows increased percentage rather than ethyl acetate. 


\section{Efflux pump}

\section{Preliminary efflux pump assay-accretion of ethidium bromide}

Bacterial cells were spotted on solid Nutrient agar medium (control) supplemented with $100 \mu \mathrm{g} / \mathrm{ml}$ of ethidium bromide. The plates were examined under UV accrual of ethidium bromide in bacterial cells after $24 \mathrm{~h}$ incubation at $28^{\circ} \mathrm{C}$ [9].

\section{Ethidium bromide accumulation assay}

To determine the efflux pumps activity, the accumulation assay of Ethidium bromide was performed with $10 \mathrm{ml}$ of early Log phase culture centrifuged and the supernatant was discarded. The pellets were washed twice with phosphate buffer saline (PBS) to remove the cell debris and other contaminants. Finally, $10 \mathrm{ml}$ of PBS was added to the pellet and vortexed well. $20 \mu \mathrm{l}$ of Ethidium bromide was taken from stock solution $(10 \mathrm{mg} / 1 \mathrm{ml})$, added to the $10 \mathrm{ml}$ of bacterial suspension and kept in rotary shaker at $150 \mathrm{rpm}$. At every $15 \mathrm{~min}$ interval, $1 \mathrm{ml}$ of culture was taken and centrifuged at $10,000 \mathrm{rpm}$ for $5 \mathrm{~min}$. Cell free supernatant was taken and OD value was measured at $600 \mathrm{~nm}$ [10].

\section{Ethidium bromide efflux assay}

To confirm the efflux pumps activity, the efflux assay was performed using ethidium bromide. $10 \mathrm{ml}$ of early log phase culture was
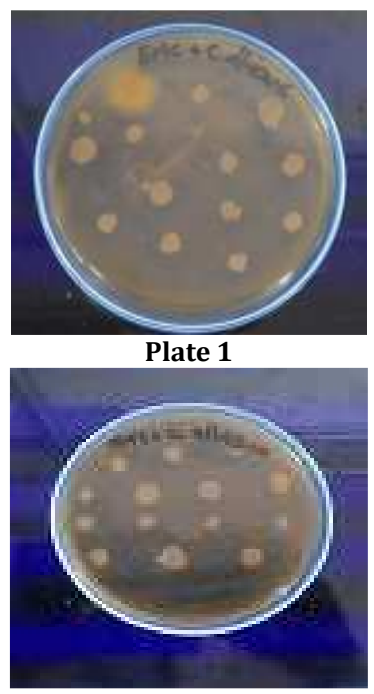

Plate 3 centrifuged, and the supernatant was discarded. The pellets were washed twice and suspended in $10 \mathrm{ml}$ of PBS with increasing concentration of glucose $(10,50,100$ and $1000 \mathrm{mmol}) .20 \mu \mathrm{l}$ of ethidium bromide stock solution ( $1 \mathrm{mg} / 1 \mathrm{ml}$ ) was added to the culture and shaken at $150 \mathrm{rpm}$ for $1 \mathrm{~h}$. At every $15 \mathrm{~min}$ regular interval, $1 \mathrm{ml}$ of culture was taken and centrifuged at 10,000 rpm for $5 \mathrm{~min}, 1 \mathrm{ml}$ of supernatant was taken and OD values were observed at $600 \mathrm{~nm}$ [10].

\section{RESULTS AND DISCUSSION}

\section{Efflux pump assay}

The aim of this work was to analyze the role of efflux pumps in providing the antibiotic tolerance/resistance of microbes. Sensitivity assay sufficiently substantiate the efficacy of both the extracts as antibacterial agent. However, the extract doesn't have effect upon fungal strains tested. This may be due to the resistance and thereby the current study focused on effluxing ability of fungi. The existence of antibiotic efflux pumps was analyzed by ethidium bromide accumulation $(100 \mu \mathrm{g} / \mathrm{ml})$ in microbial cells treated with selected antibiotics by exploring the fluorescence of ethidium bromide in bacteria under UV light. There was an accretion of ethidium bromide dye in antibiotic treated compared to control when examined under UV light (fig. 1).
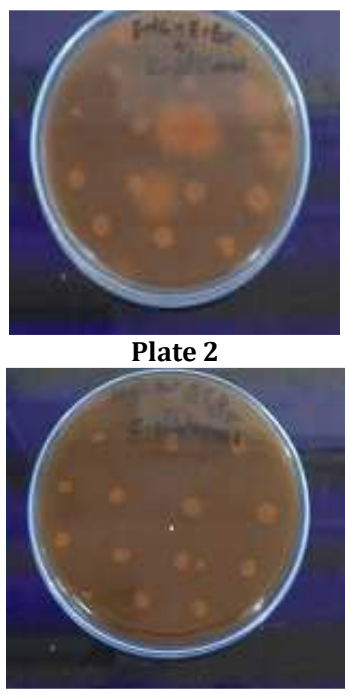

Plate 4

Fig. 1: Ethidium bromide accumulation assay on C. albicans for MMC and EMC, Plate 1: Control plate (C. albicans with EMC) under UV transilluminator, Plate 2: Accumulation of ethidium bromide in C. albicans existing with EMC under UV transilluminator, Plate 3: Control plate (C. albicans with MMC) under UV transilluminator, Plate 4: Accumulation of ethidium bromide in C. albicans existing with MMC under UV transilluminator

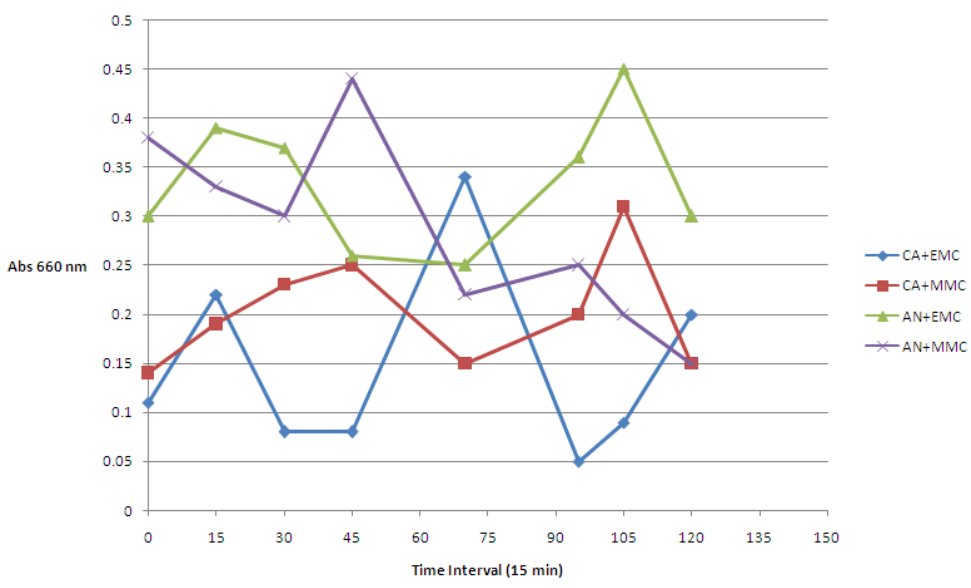

Fig. 2: Efflux pump assay, assay to determine the time taken for the maximum tolerence to MMC and EMC by Candida albicans (CA) and Aspergillus niger (AN) under the influence of glucose $1000 \mathrm{mmol}$ concentration. AN= 45/105 $\mathrm{min}$; CA= 105/75 min of MMC/EMC 
Ethidium bromide was utilized as test dye and at $15^{\text {th }}$ min after which there was a sudden decline in the accrual of dye till $30 \mathrm{~min}$ followed by gradual rise till $75 \mathrm{~min}$ and further gradual decrease in the accumulation of dye was observed. It seems that in stressful environmental conditions, bacteria are constantly under threat from stress agents and have developed protective mechanisms of siphon out wide range of antibiotics, detergents, dyes, organic solvents and heavy metals out of the cells by efflux pumps [11].

Effect of glucose concentration on effluxing ability was also analyzed fig. 2. Microbe has shown high efflux activity of ethidium bromide at $1000 \mathrm{mmol}$ (glucosecontaining PBS) followed by 100, 50 and 10 mmol compared to control (glucose free PBS).

Microbe incubated with glucose has shown high efflux activity compared to untreated. Efflux activity was observed at $45 \mathrm{~min}$ after the incubation. Efflux pumps are the proteins which extrude antibiotics, drugs and solvents out of cells. Ethidium bromide dyes are the preferred substrates for efflux pumps [12]. Efflux pump inhibitors (EPI) are the chemicals which inactivate the efflux pumps of prokaryotic and eukaryotic cells. Inactivation of efflux pumps by EPI will results in the loss of efflux activity thus results in the accumulation of antibiotics within cell which ultimately lead to the death of microbes. In view of this sensitivity assay containing combination of standard (moderately active) and extract were tested and in which remarkable results were obtained as given in fig. 3 .

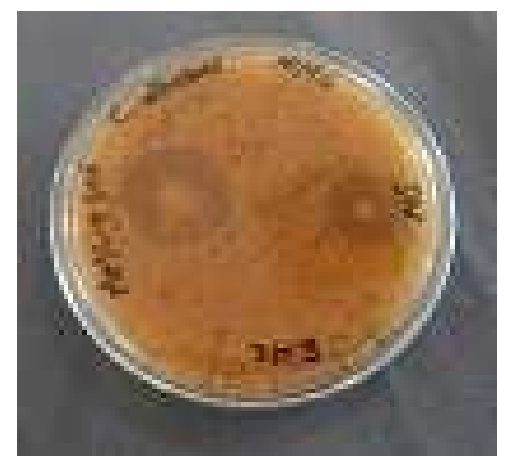

Fig. 3: Sensitivity of Candida albicans to MMC with STD, Zone of inhibition MMC+STD= $28 \mathrm{~mm}$; STD =16 $\mathrm{mm}$

\section{CONCLUSION}

Efflux pump inhibition activity of Mucunacochinchinensis seed extracts were studied and extracts showed efflux pump modulating activity. These preliminary results need for an extensive study to utilize MMC and EMC as an EPI.

\section{FUNDING}

Nil

\section{AUTHORS CONTRIBUTIONS}

All the authors have contributed equally.

\section{CONFLICT OF INTERESTS}

Declare none

\section{REFERENCES}

1. Melkamu Abebe, Senait Tadesse, Girum Meseret, Awoke Derbie. Type of bacterial isolates and antimicrobial resistance profile from different clinical samples at a referral hospital, Northwest Ethiopia: five years data analysis. BMC Res Notes 2019;12:1-6.

2. Denise E Morris, David W Cleary, Stuart C Clarke. Secondary bacterial infections associated with influenza pandemics. Front Microbiol 2017;8:1041.

3. Evans WC. Trease and evans pharmacognosy. $15^{\text {th }}$ edition. WB Saunders Edinburgh, London; 2002. p. 523.

4. Khory RN, Katrat NN. Materia medica of India and their therapeutics. Komal Prakashan, Delhi; 1999. p. 218-9.

5. Rajeshwar Yerra, Malaya Gupta, Upal Kanti Mazumder. In vitro lipid peroxidation and antimicrobial activity of Mucunapruriens seeds. Iran J Pharmacol Ther 2005a;4:32-5.

6. Manjunatha BK, Patil HSR, Vidya SM, Kekuda TRP, Mukunda S, Divakar R. Studies on the antibacterial activity of Mucunamonosperma DC. Indian Drugs 2006;43:150-2.

7. Harborne JB. Phytochemical methods. $3^{\text {rd }}$ edition. Springer (India) Pvt Ltd, New Delhi; 2005. p. 75-89.

8. Patrick J Sinko. Martins physical pharmacy and pharmaceutical sciences. $6^{\text {th }}$ edition. Wolters Kluwer (India) Pvt Ltd, New Delhi; 2010. p. 80-4.

9. Lazaroaie MM. Mechanisms involved in organic solvent resistance in gram-negative bacteria world academy of sciences. Eng Technol 2009;54:648-58.

10. Edward A, Melchias G, Visvanathan D, Prashanth Kumar Soni, Ajithan C. Role of efflux pumps in affording organic solvent tolerance to bacterial strains from petroleum contaminated soil. Middle East J Sci Res 2012;12:80-7.

11. Zgurskaya HI, Nikaido H. Multidrug resistance mechanisms: drug efflux across two membranes. Mol Microbiol 2000;37:219-25.

12. Horobin RW, Kiernan JA. Conn's biological stains. $10^{\text {th }}$ edn. Oxford, UK: BIOS Scientific Publishers; 2002. 